\title{
PerCursos
}

\section{Eventos extremos e mudança climática no discurso dos jornais Folha de São Paulo e O Globo em 2016}

\section{Resumo}

Este estudo explora uma análise dos sentidos produzidos por reportagens sobre mudança climática e eventos climáticos extremos nos jornais Folha de São Paulo e O Globo no ano de 2016. Utiliza procedimentos teóricometodológicos referentes à Análise do Discurso (Pêcheux, 1995; 2008; Orlandi, 2007). O mapeamento dos sentidos possibilitou examinar a construção discursiva de jornais de referência acerca de questões socioambientais emergentes. Por fim, essas formações indicaram a insegurança com um futuro perigoso que já vem sendo apresentado por danos catastróficos no presente, bem como a existência de enfrentamentos ineficazes e conflitos de deveres.

Palavras-chave: Jornalismo ambiental. Mudanças climáticas. Análise do Discurso. Jornalismo.

\author{
Mathias Lengert \\ Mestrando em Comunicação pela \\ Universidade Federal do Rio \\ Grande do Sul - UFRGS. \\ Jornalista pela Universidade \\ Federal de Santa Maria - UFSM. \\ Brasil \\ mathias.lengert@gmail.com
}

\section{Rosiane Zanovello}

Jornalista pela Universidade Federal de Santa Maria - UFSM.

Brasil

rosizanovello@gmail.com

\author{
Cláudia Herte de Moraes \\ Doutora em Comunicação e \\ Informação pela Universidade \\ Federal do Rio Grande do Sul - \\ UFRGS. Professora da \\ Universidade Federal de Santa \\ Maria - UFSM. \\ Brasil \\ chmoraes@gmail.com
}

\footnotetext{
Para citar este artigo:

LENGERT, Mathias; ZANOVELLO, Rosiane; MORAES, Cláudia Herte de. Eventos extremos e mudança climática no discurso dos jornais Folha de São Paulo e O Globo em 2016. Revista PerCursos, Florianópolis, v. 21, n.46, p. 54 - 82, maio/ago. 2020.
} 


\title{
Extreme weather and climate change in the discourse of the newspapers Folha de São Paulo and O Globo in 2016
}

\begin{abstract}
This study explores an analysis of the meanings produced by reports on climate change and extreme weather events in the newspapers Folha de São Paulo and $O$ Globo in the year 2016. Uses theoretical and methodological procedures related to Discourse Analysis (Pêcheux, 1995; 2008; Orlandi, 2007). The mapping of the senses made it possible to examine the discoursive construction of the reference newspapers about emerging socioenvironmental issues. Finally, these formations indicated insecurity with a dangerous future that has already been presented by catastrophic damage in the present, as well as the existence of ineffective confrontations and conflicts of duties.
\end{abstract}

Keywords: Environmental journalism. Climate change. Discourse Analysis. Journalism. 


\section{Considerações iniciais}

Em novembro de 2019, mais de 11 mil cientistas de 153 países assinaram conjuntamente um artigo declarando que o planeta está em "emergência climática", reforçando a ideia de que o aquecimento global não é comunicado com a urgência devida (RIPPLE et al., 2020). O documento sinaliza que, a despeito dos alertas realizados pela comunidade científica desde a Primeira Conferência Mundial do Clima (1979) e dos eventos e cúpulas ambientais que se seguiram, culminando com o Acordo de Paris, as emissões de gases de efeito estufa (GEE) continuam aumentando cada vez mais.

Em 2015, o Acordo de Paris se concretizou enquanto importante negociação global, celebrado no âmbito da Convenção-Quadro das Nações Unidas sobre a Mudança do Clima (UNFCCC ${ }^{1}$ ), durante a $21^{\text {a }}$ Conferência das Nações Unidas sobre as Mudanças Climáticas. O presente artigo relata parte de uma pesquisa mais ampla que investiga como os jornais brasileiros de referência Folha de São Paulo e O Globo abordaram temas relacionados à mudança climática no ano seguinte ao Acordo de Paris.

Este estudo está baseado nos pressupostos teóricos do jornalismo ambiental, ancorado na concepção de abordagem complexa das problemáticas, tendo como característica o aprofundamento do processo de apuração, não sendo considerado apenas uma especialidade, pois prioriza o comprometimento com a visão cidadã, a partir do saber ambiental e da visão sistêmica (MORAES, 2016).

A perspectiva teórico-metodológica é da Análise de Discurso de linha pecheutiana, que objetiva observar o discurso tanto como estrutura, quanto como um acontecimento (PÊCHEUX, 2008) e interpreta o modo pelo qual um objeto simbólico produz sentidos (ORLANDI, 2007). Quanto aos procedimentos analíticos, é basilar a noção-conceito de formações discursivas (FDs), que determina aquilo que pode e deve ser dito (PÊCHEUX, 1995) em determinado contexto. Em uma mesma FD estão inter-relacionadas redes parafrásticas (RPs), as quais resultam das regularidades de efeitos de sentidos. Foram coletadas 71 reportagens que se centram tematicamente em mudança climática e eventos climáticos extremos. O corpus analisado possui 261 sequências discursivas (SDs).

\footnotetext{
${ }^{1}$ Em inglês, United Nations Framework Convention on Climate Change.
} 
O gesto de interpretação empreendido alcançou quatro formações discursivas que são explicitadas na seção 4, após o detalhamento do percurso teórico e metodológico da Análise do Discurso (AD). A seção a seguir discorre das noções de Jornalismo Ambiental e de reportagem jornalística.

\section{Da crise ambiental contemporânea ao jornalismo ambiental}

Conforme se torna mais evidente a gravidade das mudanças climáticas, multiplicam-se questionamentos e a incerteza frente a uma crise que pouco é tratada com efetiva responsabilidade. "Teremos que aterrissar em algum lugar", alerta Latour (2018, p. 2, tradução nossa) sobre a ausência de planeta(s) para sustentar o consumo e terra para habitação. O projeto de um futuro comum, idealizado na resguarda do planeta para as futuras gerações pelo Relatório Brundtland³, se esvai.

As catástrofes climáticas que se acentuam nos últimos anos, exigem ações de enfrentamento urgentes que evitem ou retardem intempéries futuras, segundo estudo de Höhne et al. (2020). Para os autores, as emissões globais de GEE aumentaram 14\% entre 2008 a 2018, o que significa que é preciso diminuir as emissões destes gases em $7 \%$ ao ano, até 2030, para garantir que a temperatura média do planeta aumente apenas 1,5 ${ }^{\circ} \mathrm{C}$ até 2100, como almejado pelo Acordo de Paris.

Esses eventos que têm posto a humanidade à prova, demonstram a gravidade da crise ambiental contemporânea (LEFF, 2010), na qual a mudança do clima se configura como dimensão mais grave e profunda. Consequentemente, a questão "saltou para o primeiro plano das discussões e debates, não apenas neste ou naquele país, mas no mundo inteiro" (GIDDENS, 2010, p. 19-20), embora, por parecer intangível, ainda seja difícil tomar a iniciativa de enfrentá-la.

Com o aumento de fenômenos, crises ambientais e maior preocupação na sociedade, a temática é incorporada enquanto pauta midiática recorrente. Neste sentido,

\footnotetext{
2 "We shall have to land somewhere".

3 Publicado em 1987 pela Organização das Nações Unidas, o documento que também é intitulado "Nosso futuro comum" avançou as discussões acerca da proteção do meio ambiente e popularizou a noção de desenvolvimento sustentável.
} 
o jornalismo amplifica os debates científicos, mas também pode deixar de alertar os riscos, priorizando matérias alarmistas que substituem a cautela necessária (LOOSE; CAMANA; BELMONTE, 2017). Isso ocorre, em parte, pela grande cobertura de fatos catastróficos e dramáticos, disseminando uma impressão exagerada de risco (GIDDENS, 2010). Ainda é preciso frisar que essa construção ocorre, em primeiro momento, por critérios de noticiabilidade (TRAQUINA, 2008) com grande influência para decisão de pautas como a morte, o desastre e os conflitos.

O jornalismo busca indícios de notabilidade (ALSINA, 2009) que estão baseados, especialmente, no critério de "variação", deixando de problematizar questões complexas. "Pergunta-se o que há de novo, o que supera ou modifica algum padrão já estabelecido, sendo que não são questionados os padrões existentes." (MORAES, 2016), desta forma, foi identificada uma lógica que, segundo Benetti (2010, p. 146), se mantém como "estruturante do discurso jornalístico." Nas questões ambientais, e especialmente em relação à mudança do clima, é preciso uma alteração nessa lógica, pois a mudança do clima é um fenômeno mais lento - porém gradual e crescente ao longo do tempo, tendo perspectivas de atingir os mais pobres e vulneráveis (MORAES, 2016).

Por outro lado, o tema das mudanças climáticas atingiu um nível especial na agenda mundial e, dessa forma, o jornalismo ambiental ganha maior visibilidade especialmente por conta de o tema impor "urgência e preocupação [...] pensando no futuro dos povos." (SORHUET, 2013, p. 136). No entanto, estudos sucessivos demonstram que os temas ambientais são tratados como os demais assuntos publicados (MORAES; CORREAA, 2008; GAVIRATI, 2013; MORAES, 2016):

As notícias sobre meio ambiente normalmente se encontram no limite do Jornalismo enquanto um processo midiático, influenciado pela própria institucionalização do Jornalismo, entendida aqui como a legitimação das rotinas produtivas e dos valores a estas associados, em interação com outros atores sociais. Há, portanto, uma mobilização de diferentes esferas, de saber e de poder, aumentando a complexidade e disputas que são travadas e dirigidas ao Jornalismo. (MORAES, 2016, p. 91) 
Para Gavirati (2013), o jornalismo ambiental é conceitual, enquanto para Fernandez (2010), é preciso pensar uma divisão entre Jornalismo Ambiental Geral (a especialidade que trata do meio ambiente) e Jornalismo Ambiental "Verde" (que parte de uma visão ambiental). Dessa forma, é preciso contextualizar que o desenvolvimento do conceito de jornalismo ambiental se apresenta como um ponto de tensionamento em relação ao que se chama de "jornalismo de meio ambiente", este que é analisado na materialidade das notícias publicadas. O jornalismo ambiental é, portanto, uma forma de pensar o jornalismo, buscando colaborar para o entendimento de novas perspectivas em que a sustentabilidade seja aspecto central.

Tratando de questões ambientais é preciso considerar a necessidade do compromisso do jornalista com uma visão de mundo que não observa as problemáticas ambientais à distância, mas que investiga e traz outros dizeres ao debate público (BUENO, 2013). Assim, identifica-se que "os aportes do Jornalismo Ambiental se tornam uma possibilidade de transformação das práticas que vigoram, através da incorporação da complexidade e da incorporação de saberes até então ignorados." (LOOSE; CAMANA; BELMONTE, 2017, p. 13).

Para Dornelles (2008, p. 122) é preciso adotar um novo estilo de jornalismo que acabe com a "pseudo neutralidade e imparcialidade da imprensa." Mais que isso, a autora indica que a prática jornalística deve ser entendida para além da técnica de lidar com informações, visto que ela tem compromisso com a cidadania e a construção de um espaço público consciente de seu papel na sociedade.

Tendo em conta o entendimento do jornalismo como prática discursiva (MORAES, 2016, p. 93): “[...] pois atua sob circunstâncias peculiares na produção do discurso, a partir de uma comunidade e sob efeito ideológico de formações discursivas [...]”, na próxima seção discutem-se as bases da Análise do Discurso, dando destaque ao percurso teóricometodológico no desenho analítico dos jornais pesquisados.

\section{Análise do Discurso: percurso teórico-metodológico}

O discurso é prática simbólica da linguagem que compreende que todo sentido de 
um dizer se constitui em relação à materialidade histórica. Além disso, o efeito de sentido só existe pois há um sujeito que sustenta a possibilidade do dizer (ORLANDI, 2007). Esse sujeito do discurso, diz Pêcheux (1995), se constitui por uma relação ideológica, no liame entre linguagem e inconsciente. Esse domínio intrínseco que o autor nomeia de formação ideológica, opera na base da formação discursiva (FD) que dispõe as limitações e possibilidades de um dizer em certa época de determinada sociedade, ou seja, o sentido de um dizer se constitui necessariamente por sua inscrição em uma FD. Contudo, Pêcheux adverte, posteriormente ${ }^{4}$, que um sentido pode deslizar da formação discursiva a qual estava interpelada, tornando-se outro. Assim, “não há ritual [de interpelação ideológica] sem falhas; enfraquecimento e brechas" (PÊCHEUX, 1995, p. 301). Todo gesto discursivo é, dessa maneira, possibilidade de múltiplas relações de sentido, visto que o sujeito - e seu dizer - são sempre passíveis de deslocamentos, a partir de pontos de deriva em que um sentido se torna outro. Isso ocorre, pois, a língua está exposta ao equívoco, e a linguagem, à opacidade (PÊCHEUX, 2008).

O discurso, que para Orlandi (2007) é um objeto social fruto de um trabalho simbólico, marca a possibilidade de desestabilização no espaço de sua filiação sóciohistórica, ou seja, não há discurso que não se modifique na e pela história (PÊCHEUX, 2008). É por um já-dito que o dizer se torna possível, marcando assim, a necessária relação de um discurso com a memória, que "torna possível todo o dizer e que retorna sob a forma do pré-construído, o já-dito que está na base do dizível” (ORLANDI, 2007, p. 31). Isso significa que em toda FD, há um jogo de uma memória constituída, que no nível intertextual põe em evidência a existência do outro, isto é, que demarca a impossibilidade do sentido e do sujeito não estarem atravessados por outros sujeitos, sentidos e discursos.

Essas transposições constitutivas do jogo linguístico exprimem a heterogeneidade constitutiva da formação discursiva, decorrente de sua inscrição em um todo complexo (PÊCHEUX, 1995), no qual os discursos constituem sua identidade, em relação dependente a outros discursos (MAINGUENEAU, 1997). Assim, afirma Indursky (2005),

\footnotetext{
${ }^{4}$ A retificação de Pêcheux, "Só há causa daquilo que falha ou o inverno político francês: início de uma retificação", foi lançada, na edição brasileira, na seção de anexos do livro Semântica e Discurso.
} 
uma FD nunca é completa por si, já constituída - ao contrário, as práticas discursivas são falhas, evidenciando as contradições no dizer, as heterogeneidades de sentidos, e, portanto, tornando o fechamento de uma formação discursiva sempre instável.

Orlandi (2007) afirma que essas transformações são operadas no âmbito do embate da paráfrase e da polissemia. Os processos parafrásticos decorrem da memória, e são caracterizados pela apresentação de sentidos que se mantêm. Assim, a paráfrase representa o retorno de dizeres diversos a um “mesmo dizer estabilizado" (Orlandi, 2007, p. 36). Já a polissemia é processo simbólico de ruptura à estabilização dos mesmos dizeres. É nessa tensão que o discurso se configura como em processo de construção, acontecimental, afinal "é a condição de existência dos sujeitos e dos sentidos" (Orlandi, 2007, p. 37).

Além disso, a noção de interdiscurso funciona como o espaço em que é possível observar discursos outros que ali estão em relação de sentidos. Para Indursky (2011, p. 4), a repetição é retomada de sentidos "[...] que vão constituir uma memória que é social, mesmo que esta se apresente ao sujeito do discurso revestida da ordem do não-sabido." Essa noção complexifica o entendimento sobre as FDs, conforme Pêcheux:

[...] próprio de toda formação discursiva dissimular, na transparência do sentido que nela se forma, a objetividade material contraditória do interdiscurso, que determina essa formação discursiva como tal, objetividade material essa que reside no fato de que "algo fala" (ça parle) sempre "antes, em outro lugar e independentemente", isto é, sob a dominação do complexo das formações ideológicas. (PÊCHEUX, 1995, p. 162)

Indursky (2013, p. 91) indica que "na base das práticas discursivas de um sujeito, pré-construídos provenientes do interdiscurso, ao serem retomados, trazem consigo um determinado espaço de memória que ecoa em seu discurso." Com isso, o interdiscurso pode ser entendido "como o espaço da memória discursiva, um arquivo em que as novas produções do discurso buscam ancoragem e diálogo" (MORAES, 2016, p. 50) e até mesmo, como apontou Courtine (1981, p. 54 apud CHARAUDEAU; MAINGUENEAU; 2008, 
p. 286), se referem a "uma articulação contraditória de formações discursivas."

Após a elucidação dos principais conceitos da AD manejados neste trabalho, entende-se a importância da constituição do gesto de leitura dos analistas, explicitando as escolhas metodológicas do estudo que estão intimamente relacionadas ao caminho discutido até aqui. A questão de pesquisa busca compreender os sentidos discursivos sobre mudança do clima e eventos climáticos nos jornais Folha de São Paulo e O Globo nas reportagens publicadas no ano de 20165. A escolha dessas publicações partiu da premissa de serem jornais de referência, isto é, por servirem “interna e externamente de referência - tanto para a elite formadora de opinião, como para os meios de comunicação - sobre uma parcela do mundo público, qual seja, o país ao qual dirige" (ZAMIN, 2014, p. 939). A pesquisa se limitou à observação de reportagens ${ }^{6}$, o que acarreta a exclusão de quaisquer textos jornalísticos que não se incluem nesse gênero.

A coleta mapeou 47 reportagens que versam sobre mudança climática e 24 que abordam eventos climáticos extremos ${ }^{7}$. As reportagens apresentaram, no total, 261 sequências discursivas, sendo 176 sobre mudança climática e 85 advindas da categoria eventos climáticos extremos. Essas SDs agruparam-se em 17 sentidos possíveis, e posteriormente, foram reunidas em 8 redes parafrásticas, isto é, as marcas de regularidades do discurso, que conduziram a 4 FDs. Esse percurso está elucidado no quadro a seguir para fins de análise.

Essa etapa analítica de aglutinação de sentidos em redes parafrásticas compreende o gesto de observar nas paráfrases constituintes das sequências discursivas, a matriz do sentido. Dessa maneira, como afirmam Pêcheux e Fuchs (1997), é pelas relações efetivadas no interior da RP que se constitui o efeito de sentido.

Os textos componentes do nosso arquivo foram localizados nos acervos digitais

\footnotetext{
5 Este estudo é um recorte de um projeto de pesquisa mais amplo, e se detém, especificamente, sobre duas das sete temáticas exploradas: mudança climática e eventos climáticos extremos.

${ }^{6}$ Entende-se a reportagem, na escolha dos objetos componentes do corpus, como texto que não se detém apenas na narrativa de um fato (LAGE, 2006), mas que se preocupa com a contextualização do tema que o rodeia, sem perder o caráter informativo e capaz de ampliar a visão do público quanto a temática abordada (SODRÉ; FERRARI, 1986).

7 Das 47 reportagens da temática de mudança climática, 33 advêm do 0 Globo e 14 da Folha de São Paulo. Já, das 24 reportagens acerca de eventos climáticos extremos, 16 foram coletadas do 0 Globo e 8 da Folha de São Paulo.
} 
dos jornais, por meio de busca de palavras-chave julgadas pertinentes e relativas aos dois temas $^{8}$. Posteriormente, as sequências discursivas representativas foram recortadas e organizadas em tabelas, sem uso de software. A classificação das SDs foi realizada por leituras individuais e revisadas em grupo, organizando-se os sentidos encontrados, as RPs e, por fim, as FDs. É necessário lembrar que, com a AD, "não se objetiva interpretar o objeto submetido a ela, mas compreendê-lo em seu modo de significar. Assim, a análise não é sobre um objeto propriamente, mas sobre o processo discursivo de que ele é parte." (ORLANDI, 2013, p. 4).

Quadro 1 - Sentidos, Redes parafrásticas e Formações discursivas identificadas nos jornais Folha de São Paulo e O Globo

\begin{tabular}{|c|c|c|}
\hline Sentidos & Redes Parafrásticas & Formações Discursivas \\
\hline Incerteza & \multirow[t]{2}{*}{ Insegurança com o futuro } & \multirow[t]{4}{*}{ Perigo a caminho } \\
\hline Medo - preocupação & & \\
\hline Risco & \multirow[t]{2}{*}{ Vulnerabilidade futura } & \\
\hline Emergência & & \\
\hline Impacto ambiental & \multirow[t]{3}{*}{ Efeitos da mudança climática } & \multirow[t]{4}{*}{ Danos manifestos } \\
\hline Impacto econômico & & \\
\hline Impacto humano - social & & \\
\hline Controvérsia - conflito & Conflitos ambientais & \\
\hline Planejamento & \multirow[t]{2}{*}{ Planejamento de atitudes } & \multirow{6}{*}{$\begin{array}{l}\text { Enfrentamento da crise } \\
\text { climática }\end{array}$} \\
\hline Decisões políticas & & \\
\hline Cultura sustentável & \multirow[t]{4}{*}{ Tomada de atitudes } & \\
\hline Alternativas & & \\
\hline Tecnologia - infraestrutura & & \\
\hline Gestão - fiscalização & & \\
\hline Culpa - responsabilidade & $\begin{array}{l}\text { Culpabilidade pelas } \\
\text { problemáticas ambientais }\end{array}$ & \multirow[t]{2}{*}{ Conflito de deveres } \\
\hline Ceticismo & Questionamento & \\
\hline
\end{tabular}

8 As palavras-chave foram: mudança climática, mudança do clima, alterações climáticas, crise climática, aquecimento global, gases de efeito estufa, emissão de carbono, eventos climáticos extremos, catástrofes climáticas, desmoronamento, desastre ambiental, deslizamento, inundações, enchentes, terremoto, ressaca e seca. 


\begin{tabular}{|l|l|l|}
\hline Anti-ceticismo & dasproblemáticas ambientais & \\
\hline
\end{tabular}

Fonte: Elaborado pelos autores, 2019.

O quadro 1 permitiu a construção do percurso analítico, e no estabelecimento das SDs das subtemáticas mudança climática e eventos climáticos extremos nas categorias de RPs e FDs, sendo a categoria de Redes Parafrásticas apresentada no quadro 2.

Qadro 2 - Redes parafrásticas identificadas nos jornais Folha de São Paulo e O Globo

\begin{tabular}{|l|l|l|}
\hline Redes Parafrásticas & Mudança climática & Eventos extremos \\
\hline Insegurança com o futuro & 13 & 9 \\
\hline Vulnerabilidade futura & 61 & 17 \\
\hline Planejamento de atitudes & 13 & 4 \\
\hline Tomada de atitudes & 12 & 3 \\
\hline Efeitos da mudança climática & 38 & 42 \\
\hline Conflitos ambientais & 3 & 1 \\
\hline $\begin{array}{l}\text { Culpabilidade pelas problemáticas } \\
\text { ambientais }\end{array}$ & 34 & 9 \\
\hline $\begin{array}{l}\text { Questionamento das problemáticas } \\
\text { ambientais }\end{array}$ & 2 & 0 \\
\hline TOTAL DE SDs & $\mathbf{1 7 6}$ & $\mathbf{8 5}$ \\
\hline
\end{tabular}

Fonte: Elaborado pelos autores, 2020.

As reportagens foram observadas a fim de analisar os sentidos, ao mesmo tempo que as marcas discursivas 9 foram sondadas, para assim, apontar o tom discursivo das reportagens frente a esses temas. A verificação das marcas acarretou o mapeamento das SDs, e a seleção pelo critério de exemplaridade ${ }^{10}$.

\footnotetext{
9 As marcas discursivas podem ser verificadas por indicações em negrito em cada sequência discursiva.

${ }^{10}$ As sequências discursivas serão apresentadas em ordem cronológica de cada reportagem, quanto ao jornal, iniciando com aquelas veiculadas no O Globo e posteriormente as da Folha de São Paulo e por fim, quanto à temática, iniciando com mudança climática e indo posteriormente para eventos climáticos extremos. Devido a uma questão de espaço, nem todas as SDs mapeadas serão retratadas. Serão apresentadas apenas aquelas avaliadas como as mais representativas dos sentidos encontrados.
} 


\section{Redes de sentidos e formações discursivas}

A AD parte da superfície linguística para refletir "como um objeto simbólico produz sentidos, como ele está investido de significância para e por sujeitos" (ORLANDI, 2007, p. 26). Assim, na análise existe a necessidade de "se construir procedimentos [...] capazes de abordar explicitamente o fato linguístico" (PÊCHEUX, 2008, p. 51). Os ditos não têm apenas a finalidade de serem decodificados, mas sim de constituírem-se em pistas para compreender os sentidos que daí decorrem, em intersecção com o interdiscurso e a ideologia.

Importante destacar que, como um posicionamento epistemológico da $A D$, a interpretação é realizada a partir dos sentidos que são ofertados no discurso. Nem sempre esses sentidos estão ancorados em conhecimentos científicos ou partem de quaisquer definições de outras áreas - ao contrário, os sentidos se formam inscritos na ideologia e fazem parte da historicidade e da memória. Para Orlandi (2013, p. 1), "a interpretação é aberta e a significação sempre incompleta em seus processos de apreensão". Assim, cada interpretação é única, mas é nessa diversidade que os discursos vão sendo compreendidos em suas materialidades constitutivas, especialmente em suas filiações ideológicas.

No corpus analisado, a recorrência das redes parafrásticas (Quadro 2) destaca o baixo número de referências à discussão quanto à existência ou não da crise ambiental climática, tendo um índice muito baixo o aspecto do negacionismo ${ }^{11}$. Em estudos anteriores, esse enfoque estava presente na imprensa, especialmente nos anos seguintes à divulgação do IV Relatório do IPCC (em 2007), que apontou o aquecimento global como inequívoco, o que foi difundido com alarde pela imprensa mundial (MORAES, 2016). Em análise da Folha de São Paulo em 2015, Silva (2019) indicou ainda uma razoável presença do ceticismo na cobertura sobre o aquecimento global. De certa forma, é possível apontar uma mudança ao longo dos anos, provavelmente gradual, mas que em 2016 se mostrou mais consolidada em torno das evidências científicas das mudanças climáticas,

\footnotetext{
11 O ceticismo (autodeclarado por "céticos do clima"), por outro lado, é o mesmo que negacionismo (em outra Formação Discursiva), mas se referem àqueles indivíduos e organizações que negam (ou desacreditam) o aquecimento global.
} 
podendo estar associada ao acontecimento do Acordo de Paris, em 2015.

Ao voltar o olhar para as regularidades discursivas mais presentes no corpus, duas redes se sobressaem. A RP vulnerabilidade futura agrega 78 menções, indicando os sentidos principais de risco e emergência com maior incidência no tema mudança do clima. Nessa rede discursiva, que projeta futuros de risco ou perigo, muitas vezes se sobressaem aspectos alarmistas que, ao contrário de mobilizar, podem gerar um distanciamento em relação às ações necessárias de mitigação e adaptação climática. Um pouco dessa limitação na cobertura dos riscos, em função de sentimentos de perigo ou ameaça, ou de prevenção destes se dá em termos da lógica do funcionamento do jornalismo, que atua especialmente a partir de acontecimentos factuais (LOOSE; MORAES, 2018, p. 121). Quanto à segunda rede em destaque - RP Efeitos da mudança climática, a mesma está presente na maior parte dos textos (80 menções), porém de forma abrangente tanto da temática da mudança do clima, quanto de eventos externos, caracterizando-se um ponto positivo na explicitação dos problemas enfrentados, e das suas consequências, com os sentidos dos danos sofridos, de ordem ambiental, social e econômica.

Ao analisar os trajetos dos sentidos às redes parafrásticas, foi possível entender a organização dos discursos que direcionam a interpretação dos resultados, nos quais identificam-se quatro FDs, que serão elucidadas a seguir: FD 1 - Perigo a caminho, FD 2 Danos manifestos, FD 3 - Enfrentamento da crise climática e FD 4 - Conflito de deveres.

\subsection{Perigo a caminho}

A FD 1 - Perigo a caminho organiza sentidos que expõem o receio pelo que o futuro trará. A formação discursiva assimila a realidade iminente de riscos que a mudança climática tem oferecido a partir de relatórios científicos que indicam cenários caóticos no planeta em poucas décadas, caso nada seja feito para mitigar a questão.

A insegurança e a vulnerabilidade são firmadas a partir de um contexto social de ameaça ou de perigo potencial (LOOSE, 2015). Elas revelam uma face grave do lento, silencioso e despercebido processo de mudança climática: os desastres ambientais, que são indícios de que a vulnerabilidade humana vai se amplificar no futuro. 
Aqui se insere a problemática do que Giddens (2010) nomeia fadiga de atenção, que se refere à exaustão das informações que alertam para os perigos que a mudança climática pode trazer. Para desfazer essa armadilha, de muito falar e com isso afetar o processo social em torno do problema, o jornalismo ambiental propõe uma abordagem que dê conta da completude da trama que envolve o risco, sem esperar as tragédias e para noticiar eventos espetaculares e reducionistas das problemáticas ambientais (BUENO, 2013), afinal, “o discurso jornalístico é fundamental no processo de dar visibilidade e fomentar dadas percepções sobre os riscos climáticos” (LOOSE, 2015, p. 59).

As seguintes SDs representam esse conjunto:

SD 88: O cronômetro para o caos climático está correndo, mas a Humanidade ainda não encontrou soluções para reduzir as emissões de gases de efeito estufa. (MATSUURA, 2016a, p. 40, grifo nosso)

SD 260: Se há dúvidas com relação ao aumento da frequência de ressacas, fica a certeza de que as cidades têm de estar preparadas para o pior. Artaxo afirma que não há nenhuma perspectiva de diminuição dos eventos climáticos extremos. Pelo contrário. (ALVES, 2016, p. B9, grifo nosso)

Ambas as sequências incorporam a preocupação central da FD: a certeza que o pior está por vir e que a humanidade não está pronta para enfrentá-lo. A SD 88 apresenta uma ênfase alarmista quanto à mudança climática, ao abordar a insuficiência de tempo para reverter uma possível instauração do caos climático. É também marcada pelo pessimismo, por desprestigiar os esforços já tomados em reduzir emissões de GEE. A SD 260, em consonância com a anterior, destaca a piora do quadro dos desastres climáticos, indicando a necessidade de tomada de atitudes de mitigação e adaptação que possam contê-las ou diminuí-las.

As SDs dessa formação têm como principais sentidos a incerteza e o medo preocupação, causados pelo pânico e inquietação que o risco pode causar, representada na Rede Parafrástica 1 - insegurança quanto ao futuro. Também compõem essa FD, sentidos de risco e emergência em tomar atitudes que mitiguem as mudanças em curso, representadas da Rede Parafrástica 2 - vulnerabilidade futura. 
A RP 1 é caracterizada pelo pânico ou confusão com o quadro climático que vem sendo apresentado. As seguintes sequências são representativas dessa rede parafrástica:

SD 182: Quem sobreviveu ao desastre muitas vezes carrega o trauma da enxurrada. [...] "Tenho medo de isso aqui cair e eu passar de novo por tudo que passei. Quando chove, me ajoelho e começo a rezar". (BACELAR, 2016a, p. 12, grifo nosso)

SD 258: O problema é que não há um registro histórico detalhado nem muita informação a respeito das ressacas no litoral brasileiro, segundo Roberto Fontes, professor da Unesp de São Vicente. Daí a dificuldade em se dizer se os fenômenos aumentaram em número e intensidade nos últimos anos - seja por causa do aquecimento global ou outras mudanças climáticas. (ALVES, 2016, p. B9, grifo nosso)

A SD 182 explora a humanização e a emotividade do relato (SODRÉ; FERRARI, 1986) ao apresentar o choque e a angústia do sujeito que já sofreu um evento climático extremo. A sequência discorre sobre a insegurança que assola o próprio lar, de modo que o indivíduo recorre à fé para suportar os efeitos adversos da mudança climática.

A sequência 258 apresenta as dificuldades do campo científico em mapear os eventos climáticos extremos devido à falta de registros passados. Essa SD aponta a incerteza de definição de causas, apresentando a crise climática como fenômeno impactante e sem respostas eficazes para os questionamentos científicos.

A incerteza com as ações de mitigação evidencia a fragilidade humana, que é a temática que reúne sentidos na RP 2 - Vulnerabilidade futura, caracterizada pelo tom de discurso catastrófico quanto ao futuro no contexto climático global. As marcas dessa RP são verificadas nas seguintes sequências:

SD 3: Os eventos extremos climáticos são inevitáveis, mas não precisam resultar em desastres. Os países devem investir em técnicas para manipulação genética dos grãos, tornando-os mais tolerantes a condições naturais adversas. E também precisam reduzir a emissão de gases de efeito estufa, responsáveis pela origem das catástrofes. (GRANDELLE, 2016a, p. 21, grifo nosso) 
SD 33: Ou seja, nos próximos 25 anos, com estiagens mais longas e menos esporádicas, além de aumento de temperatura, esses locais [no Médio São Francisco] - todos com baixos indicadores sociais - são mais sujeitos a experimentar fortes perdas agrícolas, escalada de doenças, evasão de moradores e até desertificação de paisagens. (HELAL FILHO, 2016, p. 23, grifo nosso)

A terceira sequência do corpus aponta para um tom otimista, que transpassa a inevitabilidade dos eventos climáticos extremos para abordar a necessidade da tomada de atitudes que reduzam o efeito da mudança climática. Cumpre-se assim o preceito de evitar o reducionismo, alertando para o perigo, mas elencando ações a serem adotadas, como defendem Loose, Camana e Belmonte (2017).

A SD 33 ressalta a rapidez com que mudanças no clima irão atingir grupos sociais, elencando a gravidade dos efeitos que irão afetá-los. Indica também, a preocupação com o agravamento de desigualdades sociais, afinal, comunidades mais empobrecidas são as que habitam os locais com maior risco de serem atingidas (GIDDENS, 2010).

Assim, a FD 1 (Perigo a caminho) é constitutiva de sentidos que alertam para a ameaça que trará o caos climático, como descrito na SD 88. A formação discursiva é imbuída de tom dramático e catastrófico por centralizar o medo e o risco, apresentando a faceta de fragilidade humana frente aos desafios climáticos que vêm se agravando nas últimas décadas. No entanto, a necessidade do discurso jornalístico fomentar a apresentação do tema ao público (LOOSE, 2015) é satisfatoriamente realizada: é a maior FD dentre as apresentadas (a maior no subtema mudança climática com 42\% do total de SDs e a segunda maior no subtema eventos climáticos extremos com 30\% dentre o total).

\subsection{Danos manifestos}

A segunda FD - Danos manifestos trata dos efeitos causados pela crise climática de forma direta, como também indiretamente, a partir dos conflitos causados pela mudança. Essa formação discursiva possibilita nuances na discussão dos eventos catastróficos, estabelecendo uma interligação com a FD 3 - Enfrentamento da crise, ao propor a importância da mitigação, e evitando a dramatização ou a negação.

A FD é associada aos sinais visíveis da mudança climática, se amparando na voz de 
especialistas da comunidade científica que continuamente confirmam a tendência global de aquecimento do planeta. As seguintes sequências discursivas são representativas dessa FD:

SD 181: "Percebemos um movimento de pessoas voltando às suas residências condenadas, devido à morosidade das políticas públicas destinadas à vítima." [Uriel Fonseca, promotor de justiça] (BACELAR, 2016a, p.12, grifo nosso)

SD 220: Chuvas fortes? Inundações? Acostumem-se! Com as mudanças climáticas, essa é a nova realidade. (FRANÇA..., 2016, p. 27, grifo nosso)

A SD 181 trata de um conflito causado pela burocracia do governo em oferecer novos lares para moradores impactados por deslizamentos de terras que, desiludidos, voltam a residir em locais em que se sujeitam - ou como a própria sequência descreve, são condenados - a sofrer os riscos futuros em razão do desamparo governamental. Já a sequência 220, afirma que os eventos climáticos extremos não são preocupações do futuro (como tratado na FD 1), mas do presente. O imperativo "acostumem-se!" indica que essas problemáticas não são pontuais e efêmeras, mas que se tornarão cada vez mais cotidianas.

A FD 2 é composta pela RP 3 - Efeitos da mudança climática, na qual se integram os sentidos de impacto ambiental, econômico e humano - social, bem como da RP 4 Conflitos ambientais, que trata do sentido de controvérsia - conflito. A RP 3 aponta os sinais climáticos de ordem direta a partir de impactos no meio ambiente, na economia e na vida da população. As seguintes sequências exemplificam a rede parafrástica:

SD 119: Nenhum outro lugar do mundo está sendo tão afetado pelo aquecimento global quanto o Ártico, mas desta vez a situação surpreende até os mais pessimistas dos especialistas. (BAIMA, 2016, p. 36 , grifo nosso)

SD 217: "Alguns vilarejos no centro da França enfrentaram as piores enchentes em um século". (FRANÇA..., 2016, p. 27, grifo nosso) 
Ambas as sequências incorporam o alarmismo quanto à mudança climática. A SD 119 indica um viés pessimista ao afirmar que até especialistas descrentes com possíveis melhoras no quadro climático têm sido surpreendidos com os efeitos negativos do clima no Ártico. Ela se assemelha à SD 217 que apresenta as enchentes como as piores já enfrentadas. É ressaltado, desse modo, uma visão caótica de mundo.

A RP 4 indica os impactos indiretos da crise climática, exemplificados nas controvérsias científicas e conflitos humanos, quando se trata das mudanças do clima. Ela pode ser representada pela SD seguinte:

SD 4: [...] Mario Barroso acredita que a estimativa indicada pelo estudo canadense é até conservadora. Para ele os estragos causados pelo clima à produção agrícola mundial são muito mais graves. (GRANDELLE, 2016a, p. 21, grifo nosso)

A SD 4 apresenta uma controvérsia no campo científico, quanto aos impactos das problemáticas ambientais, construindo um olhar pessimista em relação aos cenários de impacto climático, ao entendê-los como mais graves do que os até então imaginados.

As características das RPs dessa formação discursiva demonstram a centralidade dos danos climáticos no cerne dessa FD. Apresentam um tom negativo e pessimista frente às dificuldades impostas, indicando assim, a postura humanitária frente ao sofrimento e à vulnerabilidade causada pelos desastres climáticos. É a segunda maior FD dentre todas, com 32\% do total de SDs. Já quando considerado apenas o subtema de eventos climáticos extremos, a formação discursiva é a maior, representando sozinha 50\% das SDs. No subtema mudança climática, sua extensão é de $23 \%$.

\subsection{Enfrentamento da crise climática}

A terceira FD trata de medidas já postas em prática ou previstas para o enfrentamento das mudanças do clima. Apresentar ações de combate à crise do clima é fundamental ao tratar de problemáticas ambientais já que se serve do desastre como possibilidade de explicar a necessidade da adoção de medidas que previnam ou reduzam os efeitos adversos desses problemas (LOOSE; CAMANA; BELMONTE, 2017). 
Elencar possibilidades de enfrentamento da mudança do clima é um grande desafio em vista da ocorrência do paradoxo de Giddens, que se refere à preocupação com as problemáticas ambientais sem, no entanto, realizar ações de combate a elas, já que elas se apresentam como abstratas e intangíveis (GIDDENS, 2010). As seguintes SDs representam esse conjunto:

SD 100: Cada um pode contribuir com a redução da pegada ecológica. Evitar andar de carro ou dedicar um dia da semana a uma dieta vegetariana, por exemplo, já que a produção de carne é bastante poluente. (MATSUURA, 2016b, p. 20, grifo nosso)

SD 208: Em março, a prefeitura anunciou um novo plano de metas até 2020. Dentre os objetivos mantém-se o da retirada de famílias que vivem em áreas de risco na cidade: o que havia sido prometido em 2003 e ainda não foi cumprido. Agora, a projeção é de que ninguém mais viva com risco de deslizamento ou enchentes até 2035. (ALTINO, 2016, p. 8, grifo nosso)

A SD 100 apresenta um incentivo na adoção de práticas que visem reduzir o impacto das mudanças climáticas. Ao propor que o sujeito-leitor tenha parcela na contribuição para a redução das adversidades que têm surgido, a sequência compreende a necessidade de defender que o sujeito seja notificado de seu papel, não o eximindo da culpa pela pegada ecológica. A SD 208, por sua vez, aborda o planejamento de ações para a retirada da população de áreas de risco. É importante observar a dificuldade em se obter sucesso na concretização da proposta, já que a finalização da meta era esperada há mais de uma década.

Essa FD é composta por duas RPs: RP 5 - Planejamento de atitudes, composta por sentidos de planejamento e decisões políticas e governamentais e RP 6 - Tomada de atitudes que envolve sentidos de alternativa, cultura sustentável, tecnologia infraestrutura e gestão - fiscalização. A RP 5 engloba ações ainda em estado de planejamento. Seus sentidos se apresentam como primeiro passo para o enfrentamento das adversidades impostas pela crise climática. A seguinte SD exemplifica essa rede parafrástica: 
SD 104: Pelo tratado, os países desenvolvidos se comprometeram a reduzir o uso de gases progressivamente, começando com um corte de 10\% (em relação aos níveis de 2011-2013), em 2019, e chegando a 85\% em 2036. [...] Estes países reivindicaram um prazo maior de adaptação para não afetar o crescimento de sua indústria, estimulado pela demanda de uma classe média em expansão. (ÉBOLI; MELLO, 2016, p. 42, grifo nosso)

A SD 104 trata do Acordo de Kigali, assinado em 2016, e que visa reduzir o uso dos gases hidrofluorocarbonetos (HFCs), com alto poder destrutivo da camada de ozônio. A negociação é uma conquista política no campo do planejamento de ações em que diversos interesses são confrontados, principalmente de países desenvolvidos que temem que suas indústrias sejam afetadas.

Em continuidade a essa rede parafrástica, a RP 6 agrega ações que já estão sendo tomadas com vista a combater as adversidades climáticas. Essas atitudes transpassam propostas globais, governamentais, empresariais, bem como, aquelas que cada indivíduo pode tomar. As seguintes SDs exemplificam essa RP:

SD 98: - Antes de Paris, manter o aquecimento em 2 graus Celsius era apenas uma ideia de alguns grupos, não um objetivo global - diz o ambientalista [Mathis Wackernagel, diretor-executivo da Global Footprint Network]. $O$ trabalho agora é de conscientizar as pessoas. Nós vemos indicações, como o desaparecimento das geleiras, mas não é suficiente. $O$ turista pode visitá-las, isso não afeta sua vida: ele volta para o hotel e janta normalmente. (MATSUURA, 2016b, p. 20, grifo nosso)

SD 107: "Ano passado em Paris, prometemos manter o mundo seguro dos piores efeitos das mudanças climáticas. Hoje, estamos cumprindo essa promessa", disse o chefe de meio ambiente da ONU, Erik Solheim, em um comunicado, referindo-se à COP-21. (ÉBOLI; MELLO, 2016, p. 42, grifo nosso)

A SD 98 apresenta o combate ao aquecimento global como pauta compartilhada pelos diversos campos da sociedade. A sequência discursiva confirma a existência de desafios, o que permite um apontamento importante dessa RP: o enfrentamento das mudanças climáticas não pode ser visto da perspectiva de alguns grupos ou instituições, 
mas sim do envolvimento de indivíduos não afetados por catástrofes climáticas. Já a SD 107 afeta o cumprimento da responsabilidade dos países com a assinatura do Acordo de Paris. Sobretudo, indica que o acordo é visto com o intento de manter a seguridade humana.

A FD 3, portanto, trata de sentidos que evidenciam a busca de soluções que possam combater a crise do clima, se destacando enquanto um contínuo processo de construção. Ao identificar e explanar o enfrentamento da mudança climática, o discurso jornalístico necessita abordar os esforços como necessários de incrementação, e assim, responsabilizar também o leitor por suas atitudes frente às adversidades climáticas. Contudo, o planejamento e a tomada de atitudes foram pouco abordados ao considerar a quantidade total de SDs mapeadas em mudança climática e eventos climáticos extremos: ela é a FD menos presente, com $12 \%$ do número total de SDs, em ambos os temas.

\subsection{Conflito de deveres}

$\mathrm{Na}$ quarta formação discursiva emergem conflitos mais politizados frente às mudanças climáticas. A FD 4 é amparada nas discussões sobre responsáveis por essas adversidades, bem como pelo questionamento de sua existência. As seguintes SDs exemplificam a FD:

SD 22: "O setor energético e de transporte estão entre os mais poluentes de nossa economia, e isso ocorre porque ainda abusamos dos combustíveis fósseis." (GRANDELLE, 2016b, p. 23, grifo nosso)

SD 47: - Queremos mostrar que a adaptação pode ser impossível ou muito cara. No caso das espécies, não há o que fazer, elas se extinguirão - alerta o climatologista José Marengo, pesquisador do Cemaden. (MARIZ, 2016, p. 29, grifo nosso)

A SD 22 trata do elevado uso de combustíveis fósseis para energia e transporte, responsáveis pela maior parte do consumo dessa fonte energética considerada suja. 0 mote da sequência discursiva se encontra justamente na impossibilidade de definir o sujeito que abusa dos combustíveis fósseis, de modo que a responsabilidade recaia, também, no leitor. Já a SD 47, com tom ceticista, questiona as possibilidades a serem 
tomadas, definindo como irrelevantes os esforços para salvar espécies animais da extinção.

A FD 4 é composta por duas RPs: RP 7 - Culpabilidade pelos problemas ambientais, que agrega o sentido de culpa - responsabilidade, e RP 8 - Questionamento da mudança climática, amparada nos sentidos de ceticismo e anti-ceticismo. A RP 7 é caracterizada por indicar culpados pela crise climática e os eventos climáticos extremos e aponta tanto para a inação de empresas e governos, como para fenômenos climáticos como o El Niño, chegando também ao próprio leitor. As seguintes SDs representam essa RP:

SD 54: Rittl considera que as mudanças climáticas "põem um holofote sobre a nossa incompetência em lidar com questões básicas." (GRANDELLE, 2016c, p. 8, grifo nosso)

SD 198: A resposta do munícipio chegou em junho: "comunicamos que é de sua responsabilidade a adoção de medidas, junto com os moradores vizinhos, para a solução do problema, por se tratar de âmbito privado", informou o governo. Na noite de sábado, a casa da família foi tomada pela lama. (BACELAR, 2016b, p. 14, grifo nosso)

A SD 54 aponta, na voz de um especialista, que a crise climática é agravada pela estagnação de indefinidas camadas da sociedade em propor medidas que contenham essa problemática. A sequência atribui ao leitor um papel importante na inação frente a essas questões, inserindo o especialista junto a ele. A SD 198, por sua vez, apresenta o desamparo governamental à população na tomada de atitudes que previnam o desastre ambiental do deslizamento. Ela é revestida por um viés catastrófico por colocar em xeque a atuação negligente da prefeitura que gerou a morte da família.

A RP 8 é fundada nos apontamentos céticos frente às mudanças climáticas, bem como nas respostas anti-céticas. Essa rede parafrástica aponta, sobretudo, para questionamentos da existência e dos impactos causados pela crise climática e os eventos climáticos extremos. A seguinte SD exemplifica essa RP: 
SD 171: Os adversários da ciência climática afirmaram que as preocupações de milhares de cientistas da corrente dominante sobre o futuro se baseiam em previsões de computador não comprovadas. (GILLIS, 2016, p. NY2, grifo nosso)

A SD 171 revela uma visão ceticista argumentando que o quadro climático não pode, de fato, ser comprovado. Essa construção se ampara na desclassificação dos estudos que usam o computador para fornecer possíveis cenários no quadro climático, concluindo que as preocupações, por não serem comprovadas, não são necessárias.

Assim, a FD 4 é caracterizada por conflitos de opiniões amparados, na sua maioria, na voz das fontes. No seu cerne, está presente a dúvida sobre a existência e os fatores que geram determinadas adversidades. Ao tratar da RP 7, que expõe a culpabilidade, é possível entender que essa tem uma relação forte com a FD 2 que aborda os danos causados pela mudança climática, pois se baseia no relato dos efeitos para indicar responsáveis pelos danos manifestados. Já a RP 8 se concentra nas discussões politizadas sobre a falsidade ou realidade da crise climática, em processo de invalidação ou validação de outros dizeres. Essa FD representa $17 \%$ do total de SDs mapeadas no estudo.

As quatro formações discursivas que foram apreendidas nesse trajeto analítico, manifestam a emergência da temática no jornalismo, operacionalizando no interdiscurso o atravessamento de dizeres nas FDs. Os sentidos inscritos nas FDs Perigo a caminho e Danos manifestos reiteram que as catástrofes climáticas são uma realidade que precede a intensificação da gravidade do quadro climático das próximas décadas. Enquanto os sentidos recortados de reportagens categorizados em "mudança climática" atentaram com maior frequência em Perigo a caminho, alertando para a vulnerabilidade humana e a emergência do assunto, os sentidos de reportagens sobre "eventos extremos" foram inscritos na FD Danos manifestos, advertindo para perdas ambientais, econômicas e humanas de catástrofes climáticas. Essas formações discursivas estão conectadas com a FD Enfrentamento da crise climática, da qual sentidos reclamam por um planejamento efetivo por autoridades políticas e indivíduos, apontando para ações ainda insuficientes. A FD Conflito de deveres indica um debate de ideais promovido no dizer de a Folha de São Paulo e O Globo acerca de questionamentos e da culpabilidade pelas ações humanas que interferem no quadro climático. 


\section{Considerações finais}

A mudança climática e os eventos extremos associados estão ancoradas em posições ideológicas complexas, materializadas em discursos tensionantes e complementares no discurso jornalístico. Neste trabalho, o recorte priorizou a observação dos efeitos de sentidos de reportagens dos jornais de referência Folha de São Paulo e O Globo, publicadas no ano de 2016. Também, no gesto interpretativo, observa-se especialmente as formações discursivas e suas redes parafrásticas.

A abordagem contextualizadora de um assunto é possibilitada pelo gênero jornalístico reportagem, bem como a variação de sentidos que apontam para complexas formações discursivas, entrecruzadas no interdiscurso que fazem emergir as posições das discussões sociais nos textos produzidos na prática discursiva jornalística.

A Análise do Discurso como perspectiva teórica e metodológica possibilitou verificar os enlaces produzidos pelas 261 sequências discursivas, recortadas de 71 reportagens veiculadas no período. Para exemplificação do método e seu funcionamento interpretativo, foram utilizadas algumas SDs para a caracterização de quatro FDs: Perigo a caminho, Danos manifestos, Enfrentamento da crise climática e Conflito de deveres.

A FD 1 confere um tom pessimista e catastrófico ao abordar as ameaças que irão impactar o mundo no futuro. Essa formação articula sentidos de medo, preocupação e incerteza em razão do modo intangível como a crise climática se configura.

A FD 2 indica danos causados no presente e passado pela mudança do clima, indicando-a como problema do presente. Assim como a primeira FD, essa é revestida por um tom pessimista que indica o viés no qual se compreendem as catástrofes.

A FD 3 apresenta medidas de enfrentamento à crise do clima. Ela é constituída por soluções básicas e reducionistas que não compreendem a mudança do clima em sua complexidade, o que exige uma série de mudanças. Importante ressaltar que é a formação discursiva menos materializada no dizer jornalístico.

A FD 4 exibe os conflitos de deveres gerados pela crise climática e pode ser caracterizada pelo embate de diversos campos sociais com formações ideológicas 
distintas entre si. Ela se apresenta em processo de (in)validação das FDs anteriores, como também, na culpabilização pelas razões que originaram os sentidos das FDs 1 e 2.

Essas formações discursivas compõem, assim, um quadro do modo que a mudança climática e os eventos climáticos extremos são articulados discursivamente nos jornais analisados. Os sentidos filiados às quatro formações discursivas mostram a preocupação do discurso jornalístico com os desastres, bem como, alertam para as perdas, de maneira dramática, num futuro caótico. Há um crescimento na atribuição de importância à emergência climática, trazendo um ganho substancial para o debate público, mobilizando vozes de impactados e atentando aos dizeres científicos.

Este artigo buscou colaborar para o conhecimento sobre a organização do discurso jornalístico em relação à mudança climática, porém está delimitado aos jornais de referência, que ainda fornecem grande parte da informação que circula socialmente. No entanto, como possibilidades de ampliação de pesquisas correlatas, parece importante agregar o estudo de discursos que circulam nas plataformas digitais, bem como nas audiovisuais, visto a transição do consumo de produção midiática na atualidade.

\section{Referências}

ALSINA, Miquel Rodrigo. A construção da notícia. Petrópolis: Vozes, 2009.

ALTINO, Lucas. Sem prevenção. O Globo, Rio de Janeiro, ano 91, n. 30222, Caderno Barra, p. 8, 5 maio 2016.

ALVES, Gabriel. Olhos na ressaca. Folha de São Paulo, São Paulo, ano 96, n. 32001, Ciência e Saúde, p. B9, 13 nov. 2016.

BACELAR, Carina. À sombra da tragédia. O Globo, Rio de Janeiro, ano 91, n. 30106, Rio, p. 12, 10 jan. 2016a.

BACELAR, Carina. Um pedaço do céu numa noite de inferno. O Globo, Rio de Janeiro, ano 91, n. 30170, Rio, p. 14, 14 mar. 2016b. 
BAIMA, Cesar. O colapso do Ártico. O Globo, Rio de Janeiro, ano 92, n. 30427, Sociedade, p. 36, 26 nov. 2016.

BENETTI, Márcia. O jornalismo como acontecimento. In: BENETTI, Marcia; FONSECA, Virginia Pradelina da Silveira (orgs.). Jornalismo e acontecimento: mapeamentos críticos. Florianópolis: Insular, 2010. p.143-164.

BUENO, Wilson da Costa. Imprensa e mudanças climáticas no Brasil: fontes hegemônicas e pouca atenção aos conceitos. Razón y Palabra, n. 84, set./dez. 2013. Disponível em: http://www.revistarazonypalabra.org/index.php/ryp/article/view/308. Acesso em: 28 jun. 2020.

DORNELLES, Beatriz. O fim da objetividade e da neutralidade no jornalismo cívico e ambiental. Brazilian journalism research, v. 4, n. 2, p. 121-131, jul./dez. 2008. Disponível em: https://bjr.sbpjor.org.br/bjr/article/view/167. Acesso em: 24 jun. 2018.

CHARAUDEAU, Patrick; MAINGUENEAU, Dominique. Dicionário de análise do discurso. São Paulo: Contexto, 2008.

ÉBOLI, Evandro; MELLO, Paulo Thiago de. Avanço contra o aquecimento. O Globo, Rio de Janeiro, ano 92, n. 30386, Sociedade, p. 42, 16 out. 2016.

FERNANDEZ, Rogelio. La sostenibilidad: una nueva etapa en el periodismo ambiental y en el periodismo en general. DELOS, v. 3, n. 8, 2010. Disponível em: http://www.eumed.net/rev/delos/08/rfr.pdf. Acesso: 25 jan. 2020.

FRANÇA prevê prejuízo bilionário com inundação. O Globo, Rio de Janeiro, ano 91, n. 30252, Mundo, p. 27, 4 jun. 2016.

GAVIRATI, Pablo. Mediatizar el ambiente; ambientalizar los médios: tensiones en torno al discurso periodístico sobre el cambio climático. In: FERNANDEZ, Rogelio; MANCINASCHÁVEZ, Rosalba (orgs.). Medios de comunicación y cambio climático. 1 ed. Sevilla: Fénix Editora, 2013. p. 217-232.

GIDDENS, Anthony. A política da mudança climática. Tradução de Vera Ribeiro. Rio de Janeiro: Zahar, 2010.

GILLIS, Justin. EUA já sentem mudança climática. Folha de São Paulo, São Paulo, ano 96, n. 31937, The New York Times, p. NY2, 10 set. 2016.

GRANDELLE, Renato. Agricultura enfraquecida. O Globo, Rio de Janeiro, ano 91, n. 30103, Sociedade, p. 21, 7 jan. 2016 a. 
GRANDELLE, Renato. Ameaça do nitrogênio. O Globo, Rio de Janeiro, ano 91, n. 30122, Sociedade, p. 23, 26 jan. 2016b.

GRANDELLE, Renato. O mês mais quente da história. O Globo, Rio de Janeiro, ano 91, n. 30171, Sociedade, p. 23, 15 mar. 2016c.

HELAL FILHO, William. Alerta na Caatinga. O Globo, Rio de Janeiro, ano 91, n. 30131, Sociedade, p. 23, 4 fev. 2016.

HÖHNE, Niklas et al. Emissions: world has four times the work or one-third of the time. Nature, v. 579, p. 25-28, 2020. Disponível em: https://www.nature.com/articles/d41586020-00571-x. Acesso em: 22 jun. 2020.

INDURSKY, Freda. Formação discursiva: ela ainda merece que lutemos por ela? In: SEMINÁRIO DE ESTUDOS EM ANÁLISE DO DISCURSO, 2., Porto Alegre, 2005. Anais [...]. [Porto Alegre, SEAD, 2005]. Disponível em: http://anaisdosead.com.br/2SEAD/SIMPOSIOS/Fredalndursky.pdf. Acesso em: 22 maio 2019.

INDURSKY, Freda. A memória na cena do discurso. In: INDURSKY, Freda; MITTMANN, Solange; FERREIRA, Maria Cristina Leandro. Memória e história na/da análise do discurso. Campinas: Mercado de Letras, 2011. p. 67-89.

INDURSKY, Freda. O trabalho discursivo do sujeito entre o memorável ea deriva. Signo y seña, n. 24, p. 91-104, 2013.

LAGE, Nilson. Estrutura da notícia. 6. ed. São Paulo: Ática, 2006.

LATOUR, Bruno. Down to Earth: politics in the new climatic regime. Tradução de Catherine Porter. Cambridge: Polity press, 2018.

LEFF, Enrique. Discursos sustentáveis. Tradução de Silvana Cobucci Leite. São Paulo: Cortez, 2010.

LOOSE, Eloisa Beling. Pensando o Jornalismo Ambiental sob a ótica dos riscos ambientais. In: Encontro Nacional dos Pesquisadores em Jornalismo Ambiental, 3, 2015. São Paulo. Anais... São Paulo: Sesc Vila Mariana, 2015, p. 45-63. Disponível em: https://anaisenpja.files.wordpress.com/2016/01/45-63-eloisa.pdf Acesso em: 28 ago. 2020.

LOOSE, Eloisa Beling; CAMANA, Ângela; BELMONTE, Roberto Villar. A (não) cobertura dos riscos ambientais: debate sobre silenciamentos do jornalismo. Revista FAMECOS: mídia, cultura e tecnologia, v. 24, n. 3, 2017. 
LOOSE, Eloisa Beling; MORAES, Cláudia Herte de. Mudanças do clima (e de pauta!). In: GIRARDI, Ilza Maria Tourinho; MORAES, Cláudia Herte; LOOSE, Eloisa Beling; BELMONTE, Roberto Villar (orgs.). Jornalismo Ambiental: teoria e prática. 1. ed. Porto Alegre: Metamorfose, 2018. v. 1.

MAINGUENEAU, Dominique. Novas tendências em análise do discurso. Tradução de Freda Indursky. 3. ed. Campinas: Pontes, 1997.

MATSUURA, Sérgio. Combate ao efeito estufa. O Globo, Rio de Janeiro, ano 91, n. 30288, Sociedade, p. 40, 10 jul. 2016 a.

MATSUURA, Sérgio. O dia da sobrecarga. O Globo, Rio de Janeiro, ano 92, n. 30317 , Sociedade, p. 20, 8 ago. 2016b.

MARIZ, Renata. Temperatura de risco. O Globo, Rio de Janeiro, ano 91, n. 30159, Sociedade, p. 29, 3 mar. 2016.

MORAES, Cláudia Herte; CORRÊA, Aline Michelle Ferreira. Entre o susto e o esquecimento: Jornalismo Ambiental na lógica da indústria da informação. In: JORNALISMO AMBIENTAL: desafios e reflexões.1 ed. Porto Alegre: Dom Quixote, 2008. p. 210-227.

MORAES, Cláudia Herte. Rio+20 entre o clima e a economia: enquadramentos discursivos nas revistas brasileiras. Bauru: Canal 6 editora, 2016. Disponível em:

http://www.canal6.com.br/livros_loja/Ebook_Rio20.pdf. Acesso em: 18 jul. 2018.

ORLANDI, Eni Puccinelli. Análise de discurso: princípios e procedimentos. 7. ed. Campinas: Pontes, 2007.

ORLANDI, Eni Puccinelli. A materialidade do gesto de interpretação e o discurso eletrônico. Formas de mobilidade no espaço e-urbano: sentido e materialidade digital. Campinas: Labeurb: Nudecri, 2013.

PÊCHEUX, Michel. Semântica e discurso: uma crítica à afirmação do óbvio. Tradução de Eni Puccinelli Orlandi. 2. ed. Campinas: Editora da Unicamp, 1995.

PÊCHEUX, Michel. O discurso: estrutura ou acontecimento. Tradução de Eni Puccinelli Orlandi. 5. ed. Campinas: Pontes, 2008.

PÊCHEUX, Michel; FUCHS, Catherine. A propósito da análise automática do discurso: atualizações e perspectivas (1975). In: GADET, Françoise; HAK, Tony (orgs.). Por uma 
análise automática do discurso: uma introdução à obra de Michel Pêcheux. Tradução de Bethania Mariani et al. 3. ed. Campinas: Editora da Unicamp, 1997. p. 163-252.

RIPPLE, William et al. World scientists' warning of a climate emergency. BioScience, v. 70, n. 1, p. 8-12, jan. 2020. Disponível em:

https://academic.oup.com/bioscience/article/7o/1/8/5610806. Acesso em: 25 maio 2020.

SILVA, André Luiz Palmeira. Discurso midiático sobre mudanças climáticas: análise da cobertura de O Liberal e Folha de S. Paulo. 2019. Dissertação (Mestrado em Comunicação, Cultura e Amazônia) - Universidade Federal do Pará, Belém, 2019.

SODRÉ, Muniz; FERRARI, Maria Helena. Técnica de reportagem: notas sobre a narrativa jornalística. São Paulo: Summus, 1986.

SORHUET, Hernán. Periodismo ambiental, una de las claves para afrontar el cambio climático. In: FERNANDEZ, Rogelio; MANCINAS-CHÁVEZ, Rosalba (orgs.). Medios de comunicación y cambio climático.1 ed. Sevilla: Fénix Editora, 2013. p. 135-146.

TRAQUINA, Nelson. Teorias do Jornalismo: a tribo jornalística: uma comunidade transnacional. 2. ed. Florianópolis: Insular, 2008.

ZAMIN, Ângela. Jornalismo de referência: o conceito por trás da expressão. Revista Famecos: mídia, cultura e tecnologia, v. 21, n. 3, p. 918-942, set/dez 2014. Disponível em: http://revistaseletronicas.pucrs.br/ojs/index.php/revistafamecos/article/view/16716/12570. Acesso em: 09 jul. 2018. 